\title{
EPISÓDIOS PLUVIAIS EXTREMOS E A VULNERABILIDADE SOCIOAMBIENTAL DO MUNICÍPIO DE FORTALEZA: \\ Oevento do dia 27/03/2012
}

\section{EXTREME PLUVIAL EPISODES AND SOCIOENVIRONMENTAL VULNERABILITY IN THE CITY OF FORTALEZA: \\ The eventofday $03 / 27 / 2012$}

\author{
João Luís Sampaio Olímpio \\ Geógrafo, mestrando em Geografia (UFC) \\ Universidade Federal do Ceará \\ olimpio.jls@hotmail.com \\ Patrícia Mena Barreto Vieira \\ Bacharel em Serviço Social (UECE) \\ Coordenadoria Municipal de Defesa Civil de Fortaleza \\ patriciamena@gmail.com \\ Maria Elisa Zanella \\ Geógrafa, Dr. a em Meio Ambiente e Desenvolvimento (UFPR) \\ Universidade Federal do Ceará \\ elisazv@terra.com \\ Marta Celina Linhares Sales \\ Geógrafa, Dr. ${ }^{a}$ em Geografia Física (USP) \\ Universidade Federal do Ceará \\ mclsales@uol.com.br
}

\begin{abstract}
Resumo
Este artigo trata da relação entre os episódios pluviaisextremos e a vulnerabilidade socioambiental, bem como os resultados desta interaçãona organização dos espaços urbanos, tendo-se como área de estudo a cidade de Fortaleza-CE. O processo de constituição do território desta cidade implicou na ocupação de áreas ambientalmente frágeis por populações socialmente vulneráveis, resultando na formação de espaços de riscos, expostos durante os episódios pluviais intensos, como o ocorrido no dia 27.03.2012. Utilizaram-se como referenciais teóricos a abordagem socioambiental e o Sistema Clima Urbano. Objetivou-se a compreensão dos sistemas atmosféricos indutores de precipitações intensas, bem como se analisou os elementos naturais e sociais formadores dos riscos naturais e as consequências negativas sobre o espaço de Fortaleza. Constatou-se que ocorreu a associação da ZCIT, VCAS e CCM para a produção das instabilidades atmosféricas do referido dia. Foram identificados e espacializados os impactos hidrometeóricosna cidade, enfatizando-se o agravamento das condições de riscos naturais e a desorganização do espaço urbano em análise.
\end{abstract}

Geo UERJ - Ano 15, no. 24, v. 1, $1^{\circ}$ semestre de 2013 p. 181-206

ISSN: 1415-7543E-ISSN: 1981-9021

http://www.e-publicacoes.uerj.br/index.php/geouerj 
Palavras-chaves: Vulnerabilidade Socioambiental, Episódios Pluviais Extremos, Abordagem Socioambiental, SCU, Fortaleza.

\begin{abstract}
This article is about the relationship between the extreme pluvial episodes and the socioenvironmental vulnerability, as well as the results of this interaction in the organization of the urban spaces. The area of study is the city of Fortaleza-CearaState, Brazil. The process of urbanization of this cityresulted in the occupation of vulnerable environmental areas by an unprivileged socioeconomic population, resulting in the creation of spaces of risk, exposed during the intense pluvial episodes, as that happened at March, 27th 2012. It was used as theoryreferential the socioenvironmental approach and the Urban Climate System. The objective of the understanding of weather systems that induce intense rainfall, as well as were analyzed the former social and natural elements of natural risks and the negative consequences about the space of Fortaleza. It was found a combination of ZCIT, VCAS and CCM in the production of atmospheric instabilities of the day. It was identified and spatialized the hydrometric impacts in the city, emphasizing the aggravation of the natural risk conditions and the disorganized of the urban space in analysis.
\end{abstract}

Key-words: Socioenvironmental Vulnerability, Extreme Rainfall Episodes, Approach Socioenvironmental, UCS, Fortaleza.

\title{
Introdução
}

Produto das relações conflituosas entre a sociedade e a natureza, os desastres naturais são eventos cada vez mais comuns e danosos às populações, causando sentimentos e explicações diferenciadas em cada parcela da sociedade. Muitas são as hipóteses para explicá-los, normalmente apontam-se os responsáveis pelassuas manifestações, mas, infelizmente, poucos são os que se vêm como participantes deste processo e que indicamações viáveis para redução dos riscos e a solução dos problemas antes, durante e depois da ocorrência dos desastres.

O discurso no entorno dessa problemática, não se restringe mais ao meio acadêmico, mas alcança a sociedade como um todo. Na impressa, na política e nas conversas do cotidiano, temascomo desenvolvimento sustentável, mudanças climáticas e desastres naturais, outrora restritos a certos grupos intelectuais, são cada vez mais comuns. Todavia, há um notório superficialismo sobre tais questões, por vezes há o surgimento de verdades absolutas sem uma real comprovação científica, outros

Geo UERJ - Ano 15, nº. 24, v. 1, $1^{\circ}$ semestre de 2013 p. 181-206

ISSN: 1415-7543E-ISSN: 1981-9021

http://www.e-publicacoes.uerj.br/index.php/geouerj 
atribuem os impactos destes eventos a forças sobrenaturais onde o homem apresenta-se com um ser passível ao processo de constituição dos riscos, além dos exageros e subestimo por parte de grupos específicos.

Diante da magnitude dos eventos catastróficos que ocorrem em outras partes do mundo, por muito tempo afirmou-se que no Brasil não havia desastres. Mas então como explicar os atuais impactos, na verdade de longa história, que vêm atingindo o Brasil? As regiões Sul e Nordeste se reversam em períodos muito secos e muito chuvosos, no Norte os desvios pluviais apresenta-se severos, nas áreas urbanas é frequente a divulgação de notícias relacionadas às inundações e aos deslizamentos. Nestes termos, como explicar tal problemática cada vez mais frequenteem um território que dizem não haver desastres? Quem contribui para a formação destes novos cenários? São perguntas novas e cada vez mais cobradaspela sociedade, cabendo aos pesquisadores buscar as suas respostas.

Neste sentido, a procura de respostas perpassa por um conhecimento integrado que envolva as ciências naturais, sociais e exatas, de modo que cadauma possa dá sua contribuição na busca do entendimento destes novos cenários, assim como a elaboração de propostas e tecnologias para a solução da referida problemática. Entre estes ramos do conhecimento, toma destaque a Geografia Socioambiental uma vez que estase fundamenta na compreensão do meio ambiente como o produto da relaçãoentre sociedade e natureza, dada por um processo constante de transformação, resultando em estados momentâneos de harmonia e conflito. Tal abordagem expõe o cenário de constituição dos riscos, desastres e vulnerabilidadesambientais.

Neste sentido, atribuir somente à natureza os danos decorrentes dos desastres naturais é um equívoco (VEYRET; RICHEMOND, 2007). Mas cabe explicá-los a partir do papel do homem cada vez mais incisivo, em função das mudanças que proporciona sobre a dinâmica dos sistemas ambientais e na formação de sociedades vulneráveis, e principalmente de grupos específicos dentro de uma mesma sociedade.

Este cenário é marcante na cidade de Fortaleza. Situada na porção setentrional do Nordeste brasileiro, o seu sítio urbano (Figura 1) é atingido periodicamente por eventos pluviais extremos, causando a desorganização do espaço em questão. Acrescenta-se que parcela significativa da população habitante possui alta 
vulnerabilidade socioambiental, já que grupos sociais específicos residem em espaços naturais susceptíveis às adversidades dos fenômenos naturais. O crescimento espacial desordenado da cidade remonta aos séculos XIX e XX, quando a população citadina amplia-se rapidamente em decorrência das migrações rural-urbano, motivadas pelas secas que impactavam os sertões interioranos (COSTA, 2007). Tal situação retrata a ausência de um planejamento territorial em nível estadual e municipal. No primeiro caso, destaca-se a ineficácia da gestão dos desastres naturais, especificamente sobre as secas do semiárido, e em nível municipal remonta a precariedade do ordenamento urbano, ao evidenciar a ocupação de terrenos impróprios para a habitação pelas populações menos abastadas.

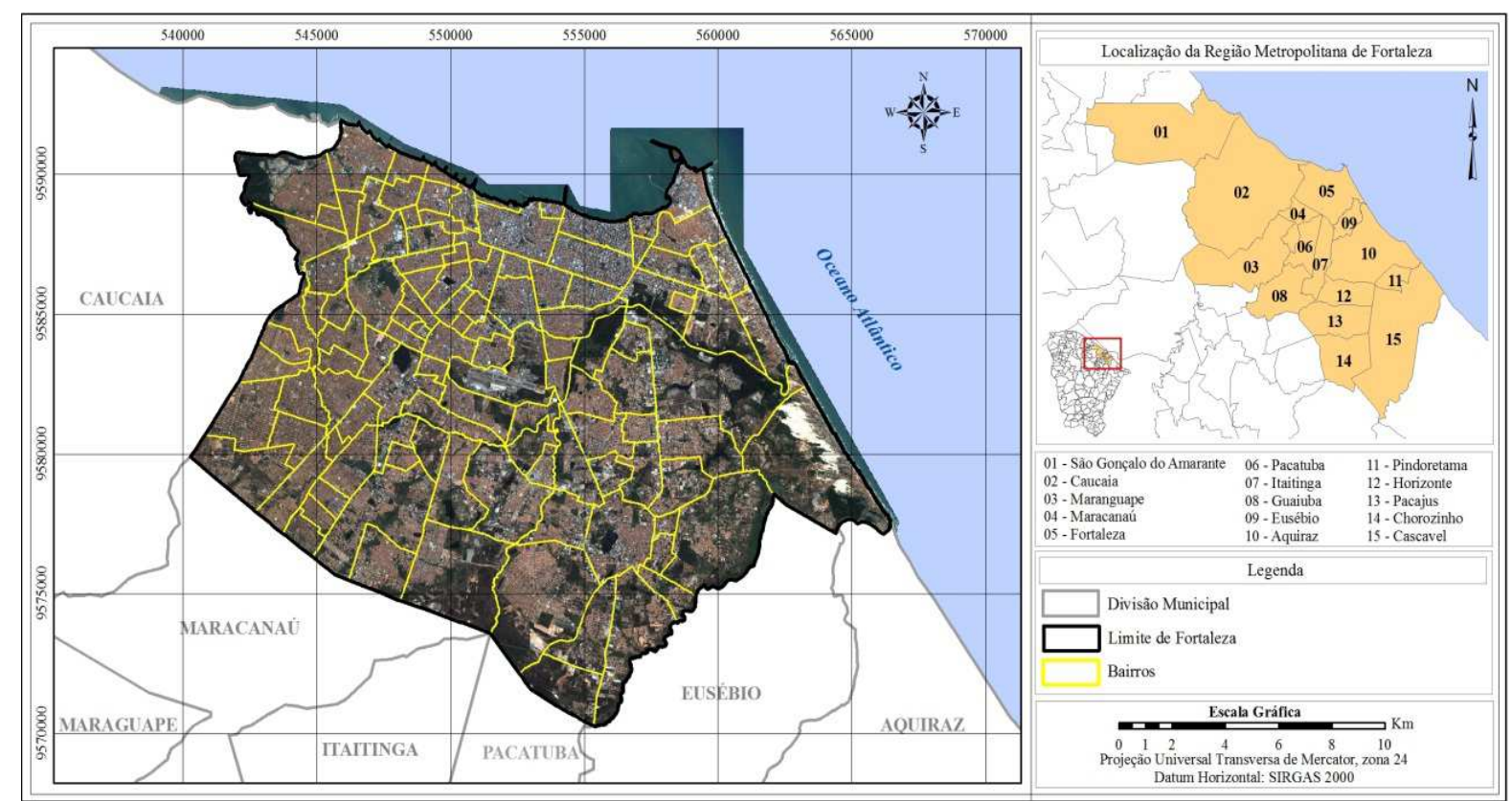

Figura 1 - Mapa de localização do município de Fortaleza.

O território de Fortaleza é marcado pela significativa diversidade social, econômica e natural, resultando em cenários ambientais diferenciados e em espaços que reagem de forma distinta às manifestações abruptas da dinâmica ambiental. Neste sentido, no espaço urbano observam-se situações de miséria e riqueza, riscos e amenidades, conflitos e harmonias, indicando a segregação socioespacial e socioambiental reinante (ZANELLA et al, 2009). 
A vulnerabilidade socioambiental desta cidade resulta do uso inadequado de determinados espaços sujeitos a uma dinâmica natural singular ou decorrente de atividades e intervenções humanas que põem em risco parcela da população. Em Fortaleza, o processo de crescimento urbano favoreceu a ocupação de ambientes frágeis,marcados por processos específicos que por vezes entram em conflito com a dinâmica social presente, de modo que periodicamente geram-se situações de crise. Ademais, a histórica carência em ações de planejamento e de ordenamento territorial não permitiram a implantação das infraestruturas necessárias às atividades urbanas, promovendo-se diversos impactos socioambientais.

Grosso modo, a vulnerabilidade socioambiental de Fortaleza é mais crítica sobre as planícies dos rios Ceará/Maranguapinho e do Cocó e na planície litorânea, os quais apresentam uma ocupação espontânea por populações socialmente vulneráveis, resultado de um processo de segregação socioambiental, historicamente vigente nas cidades brasileiras.

Inundações, alagamentos, deslizamentos e soterramentos são as principais manifestações da dinâmica natural,promovendo danos sobre os indivíduos vulneráveis. Entretanto, as condições ambientais e socioeconômicas impõem outros riscos de ordem tecnológica e social, como o risco de contaminação biológica e química, violência, desemprego/subemprego, incêndios, explosões, desabamentos, entre outros. Formam-se verdadeiras bacias de risco, que em alusão as bacias hidrográficas, são áreas para onde convergem diversos riscos (REBELO, 2008).

Nestes termos, a presente pesquisa buscou analisar a dinâmica socioambiental do espaço urbano de Fortaleza durante a ocorrência de um episódio pluvial extremo ocorrido em 27 março de 2012. Assim, através da Abordagem Socioambiental e do Sistema Clima Urbano (SCU), objetivou-se compreender a dinâmica atmosférica associando-a aos impactos promovidos no espaço urbano.

\section{Materiais e métodos}

Geo UERJ - Ano 15, no. 24, v. 1, $1^{\text {o }}$ semestre de 2013 p. 181-206 ISSN: 1415-7543E-ISSN: 1981-9021

http://www.e-publicacoes.uerj.br/index.php/geouerj 
Este trabalho fundamentou-se em dois referenciais teóricos de cunho geográfico e ambiental, a saber: a Abordagem Socioambiental, proposta por Mendonça (2002, 2004, 2010) e o Sistema Clima Urbano (SCU)elaborado por Monteiro(1976,2011).

Conforme explicita Mendonça (2002), a problemática ambiental que se configura no decorrer do século XX, exigiu novas reflexões dos geógrafos, na busca de respostas e soluções que retratem a complexidade do meio ambiente, produto construído através das inter-relações mantidas entre a sociedade e a natureza. Neste sentido, fez-se eminente a ruptura com a clássica dicotomia entre as Geografias Física e Humana, mas caminhou-se na direção de integrá-las em um todo, assim como se mostram na realidade, resultando numa Geografia dita Socioambiental.

A Abordagem Socioambiental é um referencial de cunho sistêmico e complexo, que busca a unidade do conhecimento geográfico sobre o meio ambiente, fundamentando-se no produto das relações entre os sistemas da sociedade e os da natureza, de modo que o meio ambiente encontra-se em constante processo de transformação, resultado da dinâmica socioambiental construída (MENDONÇA, 2002). Caracteriza-se pela multi e interdisciplinaridade, portanto não se limita a um método específico, mas abarca tanto os métodos das ciências sociais como os das naturais, visando o entendimento e a solução da problemática ambiental evidenciada, entretanto sem negligenciar a construção de métodos próprios, embasados na reflexão socioambiental posta.Recentemente, Mendonça (2011), traz uma reflexão acerca da abordagem dos riscos, resiliência e das vulnerabilidades socioambientais urbanas, associadas aos eventos climáticos extremos.

Com efeito, se faznecessário que o estudo sobre os riscos e desastres naturais ocorra sobre a perspectiva anteriormente apresentada, tendo em vista que tal problemática é o produto combinado em um mesmo espaço e tempo de fenômenos naturais, associados aos processos humanos que modelam o espaço natural em função de suas necessidades, com destaque ao espaço urbano, devido à intensidade das intervenções. Por vezes, esta relação produz desarmonias ainda pouco entendidas, mas geradoras de danos expressivos para ambos os lados deste conjunto.

Quanto ao SCU, este consiste em um referencial que analisa os eventos climáticos de forma sistêmica, produto das relações estabelecidas entre os elementos

Geo UERJ - Ano 15, nº. 24, v. 1, $1^{\circ}$ semestre de 2013 p. 181-206 ISSN: 1415-7543E-ISSN: 1981-9021

http://www.e-publicacoes.uerj.br/index.php/geouerj 
climáticos, naturais e os construídos pelo homem, resultando na produção de climas urbanos específicos e diferenciados do seu entorno. Assim, a compreensão do clima urbano parte do entendimento da dinâmica climática regional associada aos processos antropogênicos que modificam a superfície terrestre (MONTEIRO, 1976, 2011).

Neste referencial, a análise geográfica do clima e dos seus agentes produtores pode ser enfocada sob três grandes conjuntos do universo climático, que devem ser dirigidos aos canais da percepção sensorial humana. Assim, o SCU pode ser analisado sob os subsistemas termodinâmico, físico-químico e hidrometeórico (MONTEIRO, 1976; 2011). Este último foi empregado na presente pesquisa, visando oentendimento da variabilidade temporal e espacial das precipitações extremas e suas repercussões sobre a população fortalezense e no seu respectivo território.

Procedimentos técnico-operacionais

Foram selecionados 15 Postos de Coleta de Dados (PCD)situados na Região Metropolitana de Fortaleza (RMF), visando verificar a distribuição espacial das chuvas, correlacionando-as com os fatores atmosféricos e ambientais que influenciam nesta variabilidade. Assim,utilizou-se4 postos no município de Fortaleza, na qual serão analisados os impactos hidrometeóricos, retratando o ambiente urbano costeiro. Com relação aos demais postos,5 estavam na zona costeira dos municípios vizinhos e 6 em setores da depressão sertaneja, logo recebendo menos influência do oceano (Figura 2). Os dados foram disponibilizados pela Fundação Cearense de Meteorologia e Recursos Hídricos (FUNCEME), sendo obtidos em escala diária, de modo que foram mensurados os valores médios da série histórica, o valor acumulado para o mês de março de 2012 e os totais dos dias 27 e 28 deste mês para cada posto.

Geo UERJ - Ano 15, nº. 24, v. 1, $1^{\circ}$ semestre de 2013 p. 181-206

ISSN: 1415-7543E-ISSN: 1981-9021

http://www.e-publicacoes.uerj.br/index.php/geouerj 


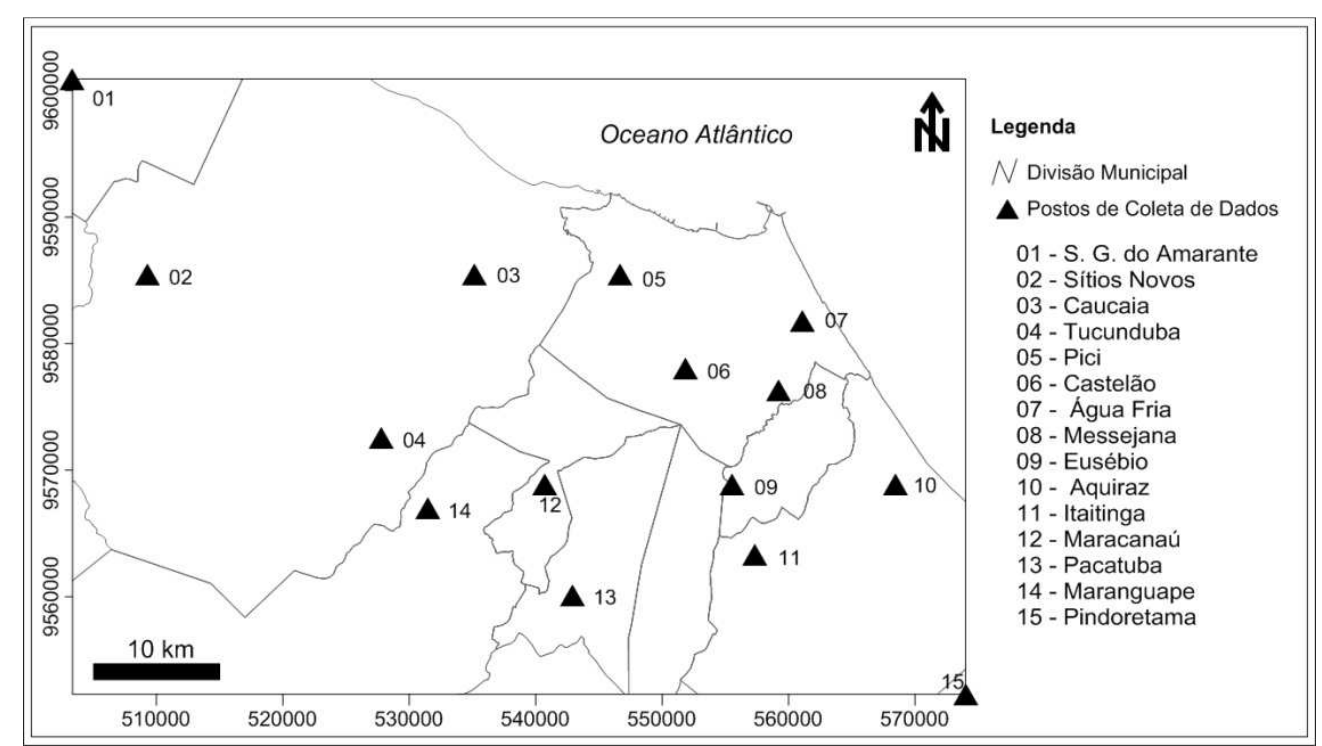

Figura 2 - Mapa de localização dos Postos de Coleta de Dados.

Após a coleta dos dados, foram realizadas tabulações no software Excel, buscando analisar a variabilidade diária das chuvas, ressaltando o comportamento habitual e excepcional das precipitações, além do exame dos valores totais no dia do episódio pluvial aqui enfatizado. Para a análise da distribuição espacial das precipitações foi empregado o software Surfer 10, adotando-se como método geoestatístico a "Krigagem". Este se baseia na Teoria das Variáveis Regionalizadas, de modo que supõe que a distribuição espacial de um determinado fenômeno é estatisticamente homogênea em uma área em análise (MARCUZZO; ANDRADE; MELO, 2011).

Também foram analisadas as imagens dos satélites meteorológicos Meteosat-9 (composição colorida) e Goes-12 (realçada), disponibilizadas pelo Centro de Previsão de Tempo e Estudo Climático (CPTEC), além da leitura das cartas sinópticas fornecidas pela Diretoria de Hidrografia e Navegação (DHN), visando interpretar a gênese e a evolução dos sistemas atmosféricos.

Com relação aos impactos hidrometeóricos, foram coletados dados de ocorrências de danos junto a Defesa Civil Municipal de Fortaleza, sendo posteriormente analisados, classificados e espacializados em um Sistema Informação Geográfica (SIG) por meio do software ArcGis 9.3. 


\section{Riscos, vulnerabilidade socioambiental e impactos hidrometeóricos}

A ocorrência de eventos pluviométricos extremosrevela o grau de vulnerabilidade socioambiental a que estáexposta cada parcela da população citadina, indicando as contradições socioespaciais e socioambientais do espaço urbanoe, consequentemente, apontaquais os indivíduos são mais susceptíveis à dinâmica natural, bem como os fatores que os colocam em situação de risco.

Entende-se por vulnerabilidade socioambiental a situação em que espaços naturais vulneráveis são ocupados por populações que não tem meios próprios ou auxílio externo efetivo para resistir e superar as adversidades dos ambientes dos quais se apropriaram, de modo que as mesmas encontram-se expostas aos riscos de desastres ambientais (DESCHAMPS, 2004; ZANELLA et al, 2009).

Conforme Deschamps (2004), a vulnerabilidade socioambiental forma-se quando populações socialmente vulneráveis habitam os espaços naturalmente vulneráveis. Assim, a autora expressa que:

Há uma estreita relação entre a localização espacial dos grupos que apresentam desvantagens sociais e aquelas áreas onde há risco de ocorrer algum evento adverso, ou seja, populações socialmente vulneráveis se localizam em áreas ambientalmente vulneráveis. (DESCHAMPS, 2004, p.140).

Mendonça (2010) ao tratar da vulnerabilidade socioambiental urbana, expõe que a mesma evidencia a heterogeneidade espacial dos riscos, relevando as diferenciações socioespaciais de cada parcela da sociedade e a complexidade do espaço urbano.

Neste sentido, a vulnerabilidade socioambiental está intimamente vinculada aos riscos de desastres ambientais. Entende por riscos ambientais a situação de probabilidade de que um evento ambiental danoso atue sobre uma população e seus bens materiais e imateriais reconhecidamente vulneráveis, causando danos e prejuízos (ISDR, 2004). Nestes termos, os riscos somente ocorrem na presença simultânea de um evento ambiental perigoso e de uma vulnerabilidade socioambiental. Portanto, são produtos das relações de mútuas entre sociedade e natureza.

Na literatura científica há uma concordância que os riscos ambientais podem ser classificados em naturais, tecnológicos e sociais, embora se reconheça que esta

Geo UERJ - Ano 15, nº 24, v. 1, $1^{\circ}$ semestre de 2013 p. 181-206 ISSN: 1415-7543E-ISSN: 1981-9021

http://www.e-publicacoes.uerj.br/index.php/geouerj 
compartimentação é meramente didática,visando a especialização do conhecimento. A realidade mostra-se mais complexa, de modo que frequentemente estes riscos ocorrem conjuntamente no mesmo espaço. Tal situação é comumente vivida pelas populações mais vulneráveis, habitantes de espaços sujeitos às adversidades dos sistemas naturais, tecnológicos e sociais ou das relações entre eles.Este trabalho foi realizado sobre os riscos naturais, especialmente sobre os originados de episódios pluviais concentrados, representando variações extremas aos padrões habituais ao ritmo climático (MONTEIRO, 2011).

\section{Dinâmica Climática Regional}

Grosso modo, as precipitações no estado do Ceará obedecem a uma sazonalidade, onde há um período curto e irregular de chuvas concentradas em 3 a 6 meses do primeiro semestre do ano, principalmente entre fevereiro a maio, seguido por um período de estiagem prolongado. Entretanto, a dinâmica climática regional caracteriza-se por uma elevada variabilidade interanual, de modo que frequentemente ocorrem desvios negativos e positivos significativos em relação às médias pluviométricas, estando relacionados com as alterações na configuração normal da circulação atmosférica global, destacando as interações oceano-atmosfera no Pacífico e no Atlântico Intertropical (MOLION; BERNARDO, 2002). Ademais, as precipitações também apresentam uma má distribuição espacial,principalmente em função dos efeitos dos fatores geográficos locais e regionais (ZANELLA, 2007). A seguir são apresentadas as características dos principais sistemas atmosféricos atuantes no estado do Ceará, destacando-se a ZCIT, o VCAS e o CCM, uma vez que a associação destes sistemas produziu o episódio pluvial extremo aqui analisado.

A Zona de Convergência Intertropical (ZCIT) é o principal sistema atmosférico responsável pela determinação da intensidade do período chuvoso. Consiste em uma banda de nuvens, formada na confluência dos ventos Alísios, sobreposta ao equador térmico, migrando entre os hemisférios ao longo do ano. No Nordeste, a ZCIT provoca chuvas de verão-outono, período no qual se encontra em sua posição mais 
meridional,resultando em uma maior convecção e aumento das instabilidades atmosféricas (FERREIRA; MELLO, 2005; MENDONÇA-DANNI-OLIVEIRA, 2007).

O Vórtice Ciclônico de Ar Superior (VCAS) corresponde a um conjunto de nuvens formadas no oceano Atlânticopelo turbilhonamento do ar em altos níveis, possuindo uma forma circular, girando em sentido horário e realizando um percurso de leste para oeste (MOURA, 2008). A borda do VCAS corresponde a uma área de baixa pressão, portanto possibilitando a formação de nuvens e a ocorrência de chuvas. Entretanto, o centro é uma área de alta pressão, onde o ar realiza um movimento de subsidência, limitando a formação de nuvens.

Os Complexos Convectivos de Meso escala (CCM) são aglomerados de nuvens formados a partir de condições locais favoráveis, como as características do relevo, pressão, temperatura, etc., gerando chuvas de curta duração e de forte intensidade, com período de vida médio de 10 a 20 horas (FERREIRA; MELLO, 2005). Nesta pesquisa, estes três sistemas são fundamentais, uma vez que a associação dos dois primeiros, em macro escala, resultou no terceiro em meso escala, produzindo uma situação atmosférica instável e geradora deuma chuva de caráter excepcional para a cidade de Fortaleza e, consequentemente, gerando diversos impactos neste território.

Também ocorrem outros sistemas atmosféricos, como asLinhas de Instabilidade, as Ondas de Leste e as brisas marítimas.No segundo semestre do ano o estado passa a sofrer a influência do Anticiclone do Atlântico Sul, associado à Massa Equatorial Atlântica,provocando estabilidade no tempo (ZANELLA, 2007).

Entretanto, a intensidade e a regularidade das precipitações encontram-se vinculadasaos padrões termodinâmicos da atmosfera acima dos oceanos Pacífico e Atlântico, criando anomalias na circulação atmosférica tropical, com destaque as perturbações nas células de Walker e Hadley, provocando desvios positivos e negativos na pluviosidade no Nordeste brasileiro. Tais alterações produzem os fenômenos oceânico-atmosféricos de El Niño/La Niña e do Dipolo do Atlântico (FERREIRA; MELLO, 2005).

O aquecimento das águas do Pacífico produz o fenômeno de El Niño, o qual tende a inibir as chuvas na região em foco, favorecendo a ocorrência de anos secos e muito secos. Em contrapartida, o resfriamento das águas gera o fenômeno La Niña,

Geo UERJ - Ano 15, nº. 24, v. 1, $1^{\circ}$ semestre de 2013 p. 181-206 ISSN: 1415-7543E-ISSN: 1981-9021

http://www.e-publicacoes.uerj.br/index.php/geouerj 
favorecendo a ocorrência de chuvas, por vezes acima das médias e, possivelmente, melhor distribuídas no tempo, resultando em anos habituais, chuvosos e muito chuvosos(XAVIER, 2011; MONTEIRO, 2011).

O Dipolo do Atlântico forma-se pela diferença de temperatura entre as águas do Atlântico Norte e Sul. Quanto as águas no Atlântico Sul estão mais aquecidas, principalmente nas áreas A e B, a situação é favorável as chuvas, no entanto, quando as águas estão mais aquecidas no Atlântico Norte, especialmente nas áreas C e D (Figura 3), há uma tendência de diminuição das precipitações (XAVIER, 2001). Porém, em anos de neutralidade do Pacífico Equatorial, não havendo o predomínio do El Niño, tampouco de La Niña, a pluviosidade encontra-se comandada pela Temperatura da Superfície do Mar (TSM) no Atlântico Equatorial. Xavier (2004) expõe que nesta situação, tanto podem ocorrer desvios positivos como negativos na pluviosidade, favorecendo a ocorrência de eventos climáticos intensos.

\section{O episódio de 27 de março de 2012}

Os episódios pluviais concentrados são fenômenos recorrentes no município de Fortaleza, fruto das influências dos eventos oceânico-atmosféricos globais sobre os sistemas atmosféricos causadores de instabilidade no espaço em análise.

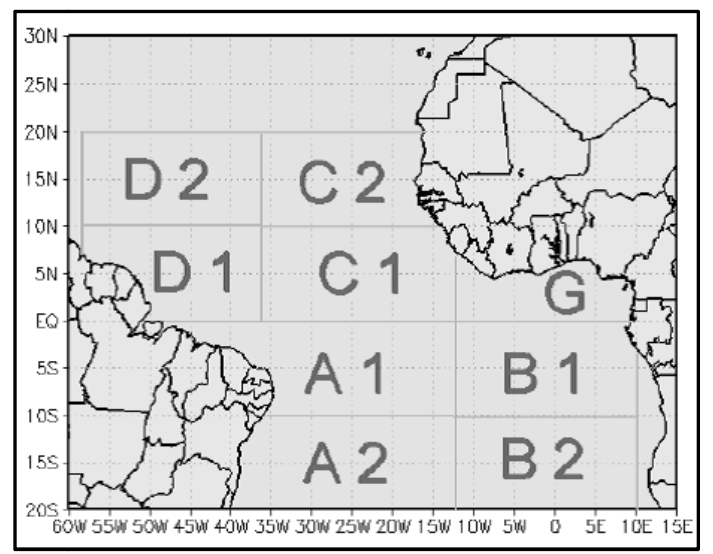

Figura 3 - Áreas para o cálculo da TSM do Atlântico Intertropical. Fonte:XAVIER, 2001. 
Zanella, Sales e Abreu (2009) identificaram queentre os anos de 1974 a 2006, ocorreram 115 episódios pluviais concentrados (> a $60 \mathrm{~mm} / 24 \mathrm{~h}$ ) e que apenas 3 anos não registraram esse tipo de episódio. Além disso, verificaram que há uma tendência de anos com maiorfrequência de episódios durante os anos de La Niña e que alguns anos com situação atmosférica diferenciada apresentaram um número significativo de episódios concentrados.

O episódio de 29.01.2004 foi analisado por Zanella e Mello (2006). Os autores constataram que este episódio foi provocado pela associação de uma ZCIT com um VCAS e que as chuvas dos dias 27 e 28 possibilitaram que as precipitações do dia do evento já encontrassem condições hidrológicas críticas.

Com relação às precipitações no ano de 2012, estas foram marcadas por uma irregular distribuição temporal, com predominância de chuvas de pouca intensidade, abaixo da situação habitual para este período do ano, resultando em uma das secas mais severas já registradas, associadasa alguns eventos pluviais concentrados.

Dos 182 dias entre janeiro a junho de 2012, 84 dias (46,15\%) não apresentaram nenhuma precipitação e $74(40,66 \%)$ registraram totais diários entre 0,1 a 10 mm em 24 horas, portanto de intensidade inexpressiva. Estas duas classes formaram o padrão pluviométrico do primeiro semestre do ano de 2012, encontrando-se bem distribuído por todos os meses, inclusive na quadra chuvosa. Em seguida, 20 dias $(10,99 \%)$ registraram precipitações entre 10 a $60 \mathrm{~mm} / 24 \mathrm{~h}$, sendo entendidas como normais ao padrão pluviométrico da região, portanto os impactos são facilmente assimilados pela sociedade. Também ocorreram dois eventos(1,10\%) entre 60 a $100 \mathrm{~mm} / 24 \mathrm{~h}$, que provocaram danos significativos, mas dentro da capacidade de suporte da população fortalezense, necessitando apenas de medidas para reduzi-los ou elimina-los. Por fim, foram registrados dois $(1,10 \%)$ eventos superiores a $190 \mathrm{~mm} / 24 \mathrm{~h}$, enquadrando-os como episódios pluviais extremos, geradores de impactos bastante expressivos, necessitando de uma gestão mais eficiente dos riscos naturais. $\mathrm{O}$ primeiro ocorreu em 27 de março, a partir da associação entre a ZCIT, o VCAS e o CCM, produzindo 196,5 $\mathrm{mm} / 24 \mathrm{~h}$, sendo este analisado na presente pesquisa. O outro episódio ocorreu 23 de junho pelas Ondas de Leste, provocando 196,6 mm/24h. Destaca-se que estas duas

Geo UERJ - Ano 15, nº. 24, v. 1, $1^{\circ}$ semestre de 2013 p. 181-206 ISSN: 1415-7543E-ISSN: 1981-9021

http://www.e-publicacoes.uerj.br/index.php/geouerj 
precipitações correspondem a $16,43 \%$ e $16,44 \%$, respectivamente, do total pluviométrico acumulado entre janeiro a julho de 2012 (Figura 4).

\begin{tabular}{|c|c|c|c|c|c|c|c|c|c|c|c|c|c|c|c|c|c|c|c|c|c|c|c|c|}
\hline Mês & Total & 1 & 2 & 3 & 4 & 5 & \begin{tabular}{l|l}
6 & 7 \\
\end{tabular} & 8 & 9 & \begin{tabular}{l|l}
10 & 1 \\
\end{tabular} & \begin{tabular}{l|l}
11 & 12 \\
\end{tabular} & 213 & \begin{tabular}{l|l}
14 & 1 \\
\end{tabular} & \begin{tabular}{|l|l|}
15 & 16 \\
\end{tabular} & 17 & \begin{tabular}{|l|l|}
18 & 19 \\
\end{tabular} & 1920 & \begin{tabular}{|l|l|}
21 & 22 \\
\end{tabular} & 2324 & 25 & \begin{tabular}{l|l|l}
26 & 27 \\
\end{tabular} & 2728 & 293 & \begin{tabular}{|l|l|}
30 & 31 \\
\end{tabular} \\
\hline Jan & 48,1 & & & & & & & & & & & & & & & & & & & & & & & \\
\hline Fev & 173 & & & & & & & & & & & & & & & & & & & & & & & X \\
\hline Mar & 489 & & & & & & & & & & & & & & & & & & & & & & & \\
\hline $\mathrm{Abr}$ & 170 & & & & & & & & & & & & & & & & & & & & & & & \\
\hline Maio & 101 & & & & & & & & & & & & & & & & & & & & & & & \\
\hline Jun & 221 & & & & & & & & & & & & & & & & & & & & & & & \\
\hline & & \multirow{2}{*}{\multicolumn{23}{|c|}{ Dias sem chuvas }} \\
\hline \multirow{5}{*}{\multicolumn{2}{|c|}{ Legenda }} & & & & & & & & & & & & & & & & & & & & & & & \\
\hline & & \multicolumn{23}{|c|}{ Dias com chuvas entre $0,1 \mathrm{a} 10 \mathrm{~mm}$, em 24 horas } \\
\hline & & \multicolumn{23}{|c|}{ Dias com chuvas entre 10 a $60 \mathrm{~mm}$, em 24 horas } \\
\hline & & \multicolumn{23}{|c|}{ Dias com chuvas entre 60 a $100 \mathrm{~mm}$, em 24 horas } \\
\hline & & & \multicolumn{22}{|c|}{ Dias com chuvas acima de $190 \mathrm{~mm}$, em 24 horas } \\
\hline
\end{tabular}

Figura 4 - Dias com chuvas entre janeiro a junho de 2012, por intensidade em 24 horas. Fonte de Dados: FUNCEME - Posto Meteorológico do Campus do Pici.

O episódio do dia 27.03.2012 foi provocado pela atuação conjunta da ZCIT associada ao VCAS (Figura 5). Neste dia, a ZCIT encontrava-se compartimentada em uma banda dupla de nuvens, uma principal sobre o oceano Atlântico, em torno de $2^{\circ} \mathrm{N}$, e outra secundária, próxima àzona costeira nordestina, entre $2^{\circ}$ a $3^{\circ} \mathrm{S}$. Este sistema foi atraído pela periferia doVCAS, formado durante a madrugada, de modo que um conjunto de nuvens carregadas migrou sobre a costa cearense.
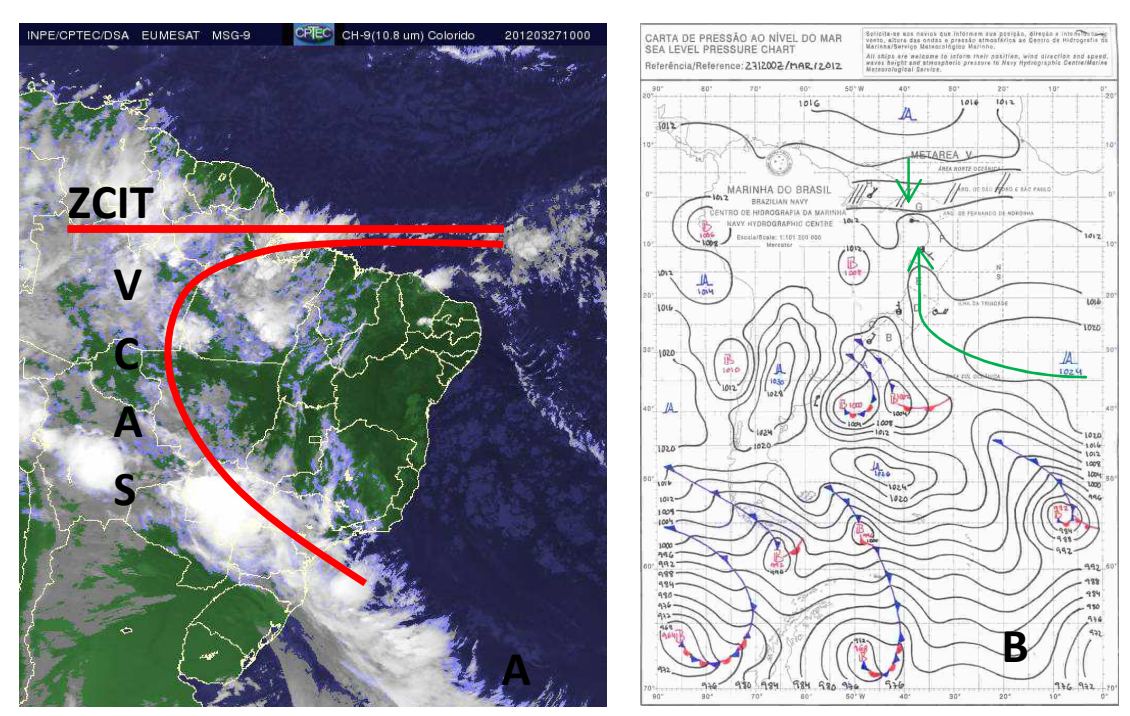

Geo UERJ - Ano 15, nº. 24, v. 1, $1^{\circ}$ semestre de 2013 p. 181-206

ISSN: 1415-7543E-ISSN: 1981-9021

http://www.e-publicacoes.uerj.br/index.php/geouerj 
Figura 5 - Configuração atmosférica sobre o Brasil em 27 de março de 2012. A) Imagem meteorológica, obtida pelo sensor Meteosat9. B) Carta Sinóptica. Fonte:

CPTEC/INPE, Marinha do Brasil.

Entretantouma análise, em escala regional, da evolução do evento permite identificar a formação de um CCM, sobre o mar, próximo à costa cearense. Em seguida, este sistema migrou para o continente, adentrando pela costa de Fortaleza e dos municípios vizinhos, encontrando condições adequadas que o intensificaram, provocando instabilidades no tempo por aproximadamente14horas.No final da tarde, o sistema enfraquece e se desloca sobre a costa, em direção ao Rio Grande do Norte (Figura 6).

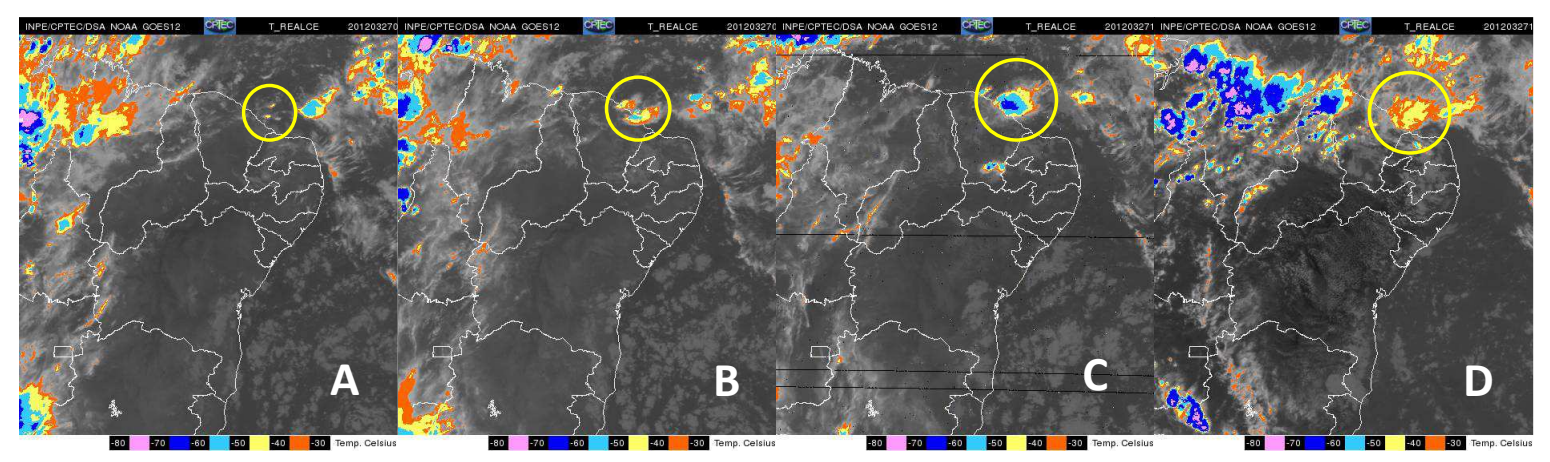

Figura 6 - Formação e evolução do CCM. A - 00h:00min; B - 02h:30min; C 07h:00min; D - 15h:45min. Fonte: satélite Goes-12, CPTEC/INPE.

Este sistema contribuiu significativamente para a pluviosidade mensal, de forma que o mês de março de 2012 apresentou um total pluviométrico de 55,98\% acima da média mensal (313,22 mm - Estação Meteorológica do Campus do Pici). Contudo, esta situação de chuvas acima das médias é aparente, tendo em vista que as chuvas concentraram-se no dia 27 e secundariamente no dia 28, representando 40,42\% e $18,42 \%$ da precipitação mensal, sendo que nos demais dias as chuvas foram bem inferiores (Gráfico 1). Ressalta-se que em função do horário de coleta dos dados, o total precipitado ficou compartimentado entre os dias 27 e 28 , porém a chuva aconteceu em menos de 24 horas.

Geo UERJ - Ano 15, no. 24, v. 1, $1^{\circ}$ semestre de 2013 p. 181-206 ISSN: 1415-7543E-ISSN: 1981-9021

http://www.e-publicacoes.uerj.br/index.php/geouerj 


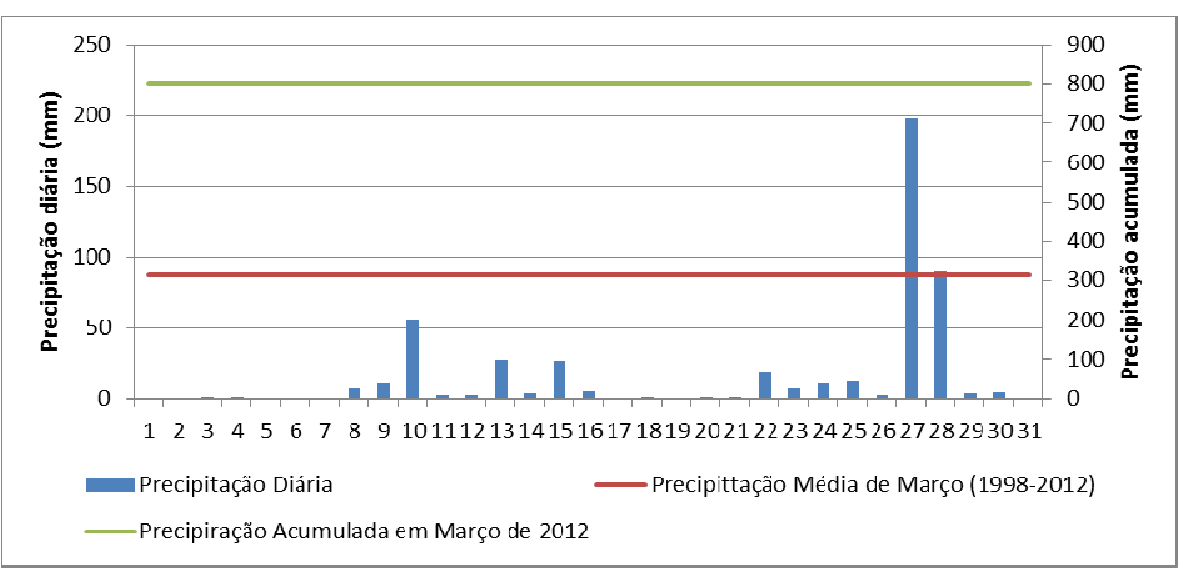

Gráfico 1- Pluviosidade do mês de março de 2012. Fonte de Dados: FUNCEME Estação Meteorológica do Campus do Pici.

Com relação à distribuição espacial das precipitações, observa-se uma expressiva variabilidade, situação comum na região do semiárido nordestino, porém pouco discutida em escala de maior detalhe. Tal diferenciação ocorre em função de fatores geográficos locais que favorecem ou inibem as precipitações em uma determinada região.

Magalhães e Zanella (2011) demostram que na RMF há uma concentração de precipitações na faixa litorânea dos municípios de Fortaleza, Eusébio e leste de Caucaia, reduzindo-se à medida que se adentra no interior do estado. Conforme os autores, isto decorre da disposição geográfica da costa, a qual recebe sistemas atmosféricos oriundos do oceano (Linhas de Instabilidades, Ondas de Leste, brisas marítimas), as quais adentram com direção predominantemente de NE. Acrescenta-se que a topografia plana da zona costeirapermite que os sistemas penetrem em setores mais afastados do oceano. Este quadro pode ser observado na análise da média pluvial do mês de março, o qual apresenta valores superiores na costa oeste de Fortaleza, de Aquiraz e leste de Caucaia, ultrapassando a isoieta $310 \mathrm{~mm}$ médiamensal, entretanto, as chuvas tendem a diminuir em direção ao setor sudoeste,com valores médios próximos a $150 \mathrm{~mm}$ mensais, sendo a amplitude entre os extremos da ordem de 170 mm (Figura 7). 


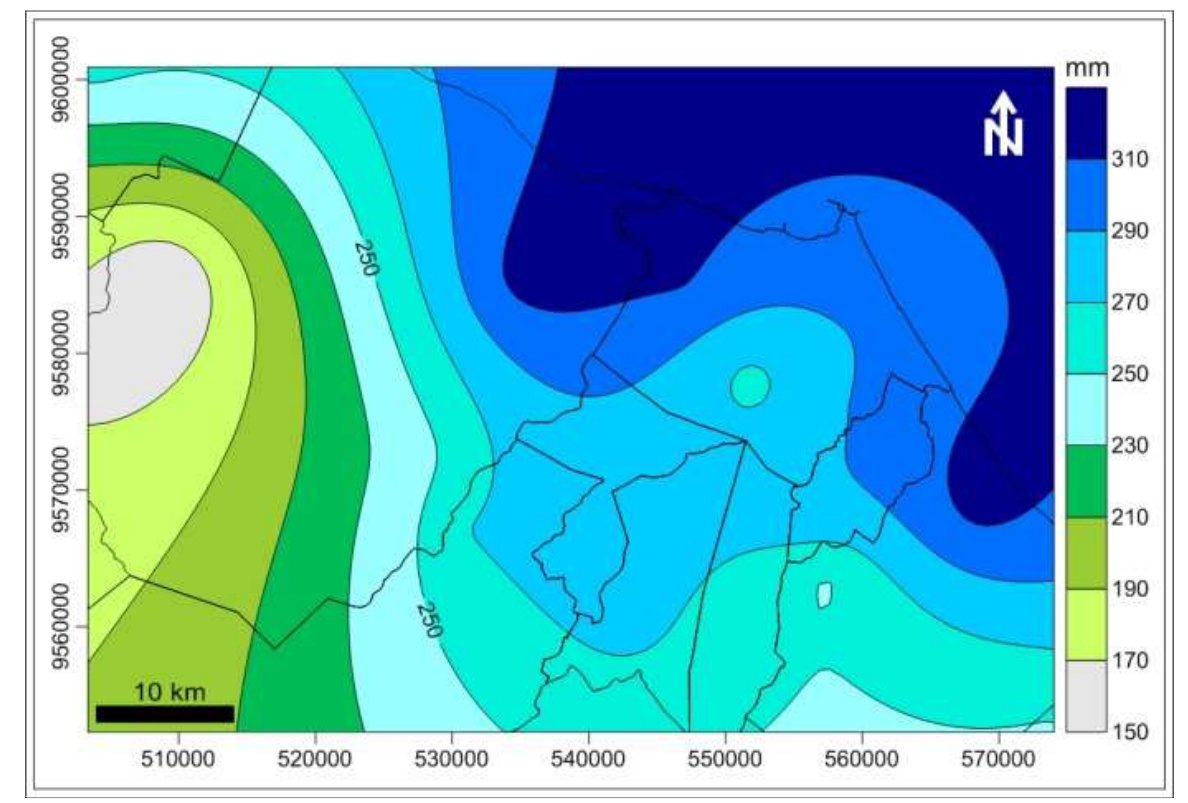

Figura 7 - Mapa da distribuição espacial da precipitação média mensal de março. Fonte de dados: FUNCEME.

No que tange ao mês de março de 2012, nota-se que a distribuição das precipitações foi semelhante ao descrito anteriormente, contudo observa-se uma concentração das chuvas no setor oeste de Fortaleza, com valores superiores a $480 \mathrm{~mm}$ mensal (Figura 8). Todavia, o sudoeste de Caucaia, região com valores pluviométricos médios inferiores, em março de 2012 apresentou totais ainda mais reduzidos, de modo que a amplitude pluviométrica intensificou-se, apresentando $371,0 \mathrm{~mm}$ entre os extremos. Esta configuração foi motivada pelo sistema atmosférico do dia 27, o qual atingiu, sobretudo, o setor oeste de Fortaleza, estacionando sobre a costa deste município, de modo que as chuvas foram pouco sentidas nas áreas mais interioranas. Para enfatizar o reduzido total precipitado neste ano, destaca-se que a isoieta de $150 \mathrm{~mm}$ deslocou-se aproximadamente $20 \mathrm{~km}$ para sul e para oeste.

Os registros de precipitação acumulada entre os dias 27 e 28 de março indicam uma irregular distribuição espacial das chuvas, de modo que o sistema atmosférico apenas atingiu o caráter de evento extremo nos setor oeste de Fortaleza (PCD Pici) e leste de Caucaia (PCD Caucaia), em decorrência do total precipitado, 287,5 mm e 170,4 $\mathrm{mm}$, respectivamente (Gráfico 2; Figura 9). 


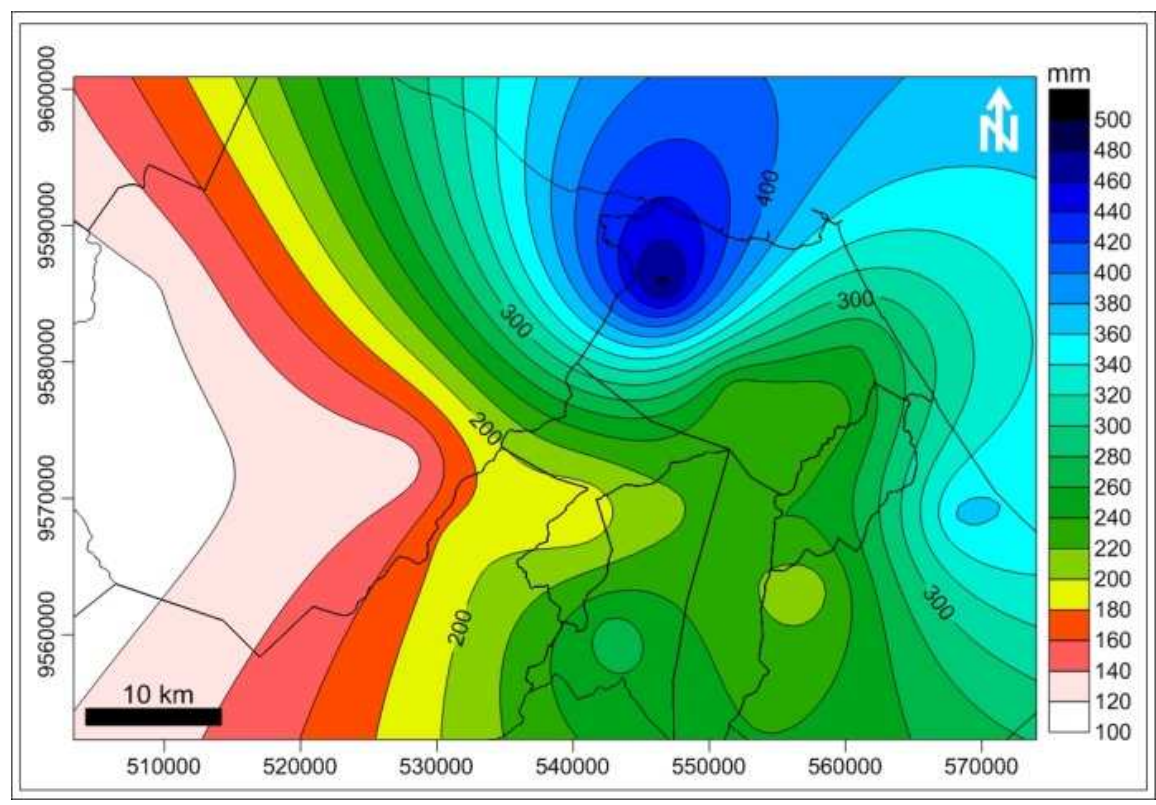

Figura 8- Mapa da distribuição espacial da precipitação acumulada em março de 2012. Fonte de dados: Funceme.

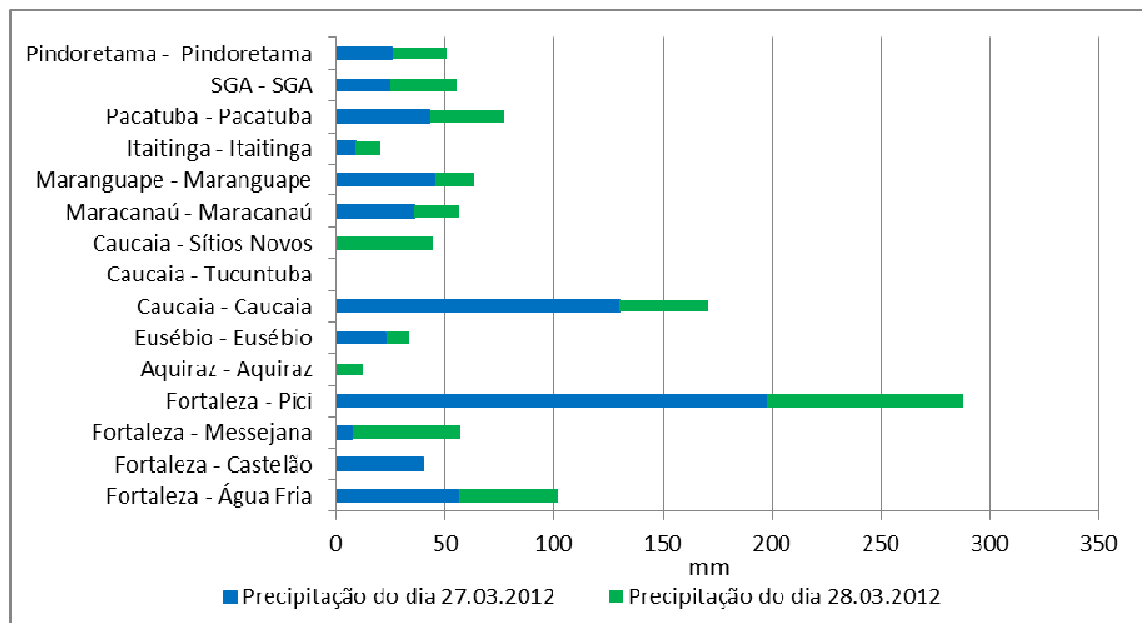

Gráfico 2 - Total precipitado nos dias 27 e 28 de março de 2012 nos PCDs da RMF. Fonte de dados: Funceme.

Ressalta-se que alguns postos registraram precipitações reduzidas e elevada amplitude em relação ao valor extremo do posto Pici, o que indica que as chuvas extremas apenas ocorreram em uma porção espacial restrita. O posto Tucunduba, situado na porção sul do munícipio de Caucaia, que normalmente apresenta totais inferiores aos registrados na zona costeira, nos dias27 e 28 não obteve nenhuma precipitação, indicando que o sistema não penetrou em porções mais interioranas do

Geo UERJ - Ano 15, no. 24, v. 1, $1^{\circ}$ semestre de 2013 p. 181-206 ISSN: 1415-7543E-ISSN: 1981-9021

http://www.e-publicacoes.uerj.br/index.php/geouerj 
setor oeste da área em análise. O posto de Aquiraz, no município homônimo, o qual também se encontra na zona costeira, apresentando médias pluviais bastante elevadas (segunda média pluviométrica mais elevada com 318,35 mm mensais) registrou apenas o valor de $12,4 \mathrm{~mm}$ no dia 28 , provocado pela nebulosidade do CCM, mas quando este já se encontrava enfraquecido e migrando para o litoral do Rio Grande do Norte.

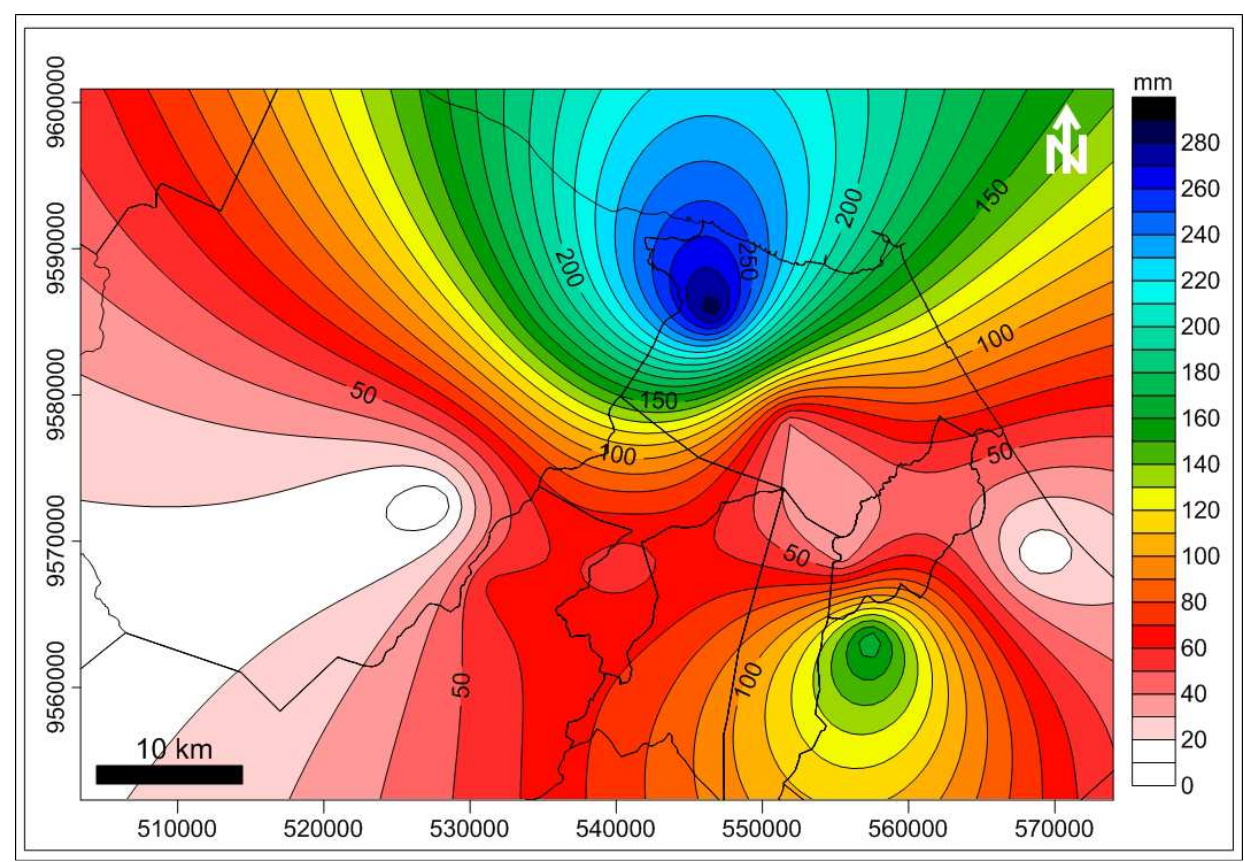

Figura 9 - Mapa do total acumulado das precipitações dos dias 27 e 28 de março de 2012. Fonte de dados: Funceme.

No dia 27 também foram registradas precipitações inferiores nos postos Castelão (40,0 mm/24h), Messejana $(7,2 \mathrm{~mm} / 24 \mathrm{~h})$ e Água Fria $(56,0 \mathrm{~mm} / 24 \mathrm{~h})$, todos em Fortaleza, distando do posto de Pici, 8,9, 15,5 e 14,9 Km, respectivamente. Os postos de São Gonçalo do Amarante e de Sítios Novos, localizados no extremo oeste da área em análise, apresentaram precipitações superiores no dia 28 , devido à nebulosidade associada à ZCIT, atuante neste dia, ressalta-se que no dia 27 os valores precipitados foram de 25,0 e $0,0 \mathrm{~mm}$ em $24 \mathrm{~h}$, indicando que o CCM pouco atuou nesta região. No total acumulado podem ser observadas precipitações intensas nos postos de Maranguape $(63,2 \mathrm{~mm})$ e Pacatuba $(77,0 \mathrm{~mm})$, resultando dos efeitos orográficos das serras de Maranguape e Aratanha. 
Neste sentido, os registros pluviométricos apresentaram elevada amplitude, com máximo no posto de Pici $(287,5 \mathrm{~mm})$ e mínimo em Tucunduba $(0,0 \mathrm{~mm})$, estando 22,5 $\mathrm{km}$ um do outro.

\section{Impactos hidrometeóricos e vulnerabilidade socioambiental}

As chuvas ocorridas durante o dia 27 de março provocaram danos e prejuízos significativos na cidade e na população fortalezense, especialmente naquela usuária de espaços considerados social e ambientalmente vulneráveis, portanto estando sujeita à dinâmica hidroclimatológica decorrente deste evento, bem como apresentando condições sociais, econômicas, culturais e físico-estruturais que inibem a capacidade de resistência e resiliência dos citadinos.

A análise dos registros de ocorrências da Defesa Civil Municipal de Fortaleza para o dia 27 de março aponta que os impactos concentraram-se, principalmente, sobre a bacia hidrográfica do rio Maranguapinho/Ceará,correspondendo àregião de Fortaleza predominantemente habitada por uma população socialmente mais vulnerável, estando exposta às inundações e aos alagamentos (Figura 10). Ressalta-se que, como demonstrado anteriormente, o sistema atmosférico indutor destes impactos ocorreu com mais intensidade justamente sobre está porção de Fortaleza.

Neste sentido, observa-se que embora a magnitude do sistema atmosférico seja extrema, os danos resultantes foram mais significativos em função da baixa capacidade de resistência, resiliência e de ajustamento da população frente às manifestações do evento natural. Acrescenta-se a má gestão dos riscos naturais, ainda pouco desenvolvida pelo Poder Público e pela própria sociedade civil, estando as ações centradas na etapa de resposta, sendo as medidas preventivas tímidas e pouco eficientes.

Nas demais bacias os impactos não foram frequentes, mas apresentando considerável número de registros no setor norte da cidade, provocados predominantemente por alagamentos. Na bacia do rio Cocó foram pouco significativos, estando relacionados às inundações e ao risco de desabamento.

Geo UERJ - Ano 15, no. 24, v. 1, $1^{\circ}$ semestre de 2013 p. 181-206 ISSN: 1415-7543E-ISSN: 1981-9021

http://www.e-publicacoes.uerj.br/index.php/geouerj 
Ao todo foram registradas 154 ocorrências, sendo as inundações e os alagamentos os eventos que mais geraram danos, consequentemente desorganizaram o espaço e afetaram, direta e indiretamente, todas as atividades urbanas (Tabela 1). A manifestação destes impactos hidrometeóricos resultou em diversos transtornos, como a perda de utensílios domésticos, desabamentos, comprometimento do sistema de circulação viária, trânsito confuso, prejuízos nas atividades econômicas, além do comprometimento da saúde pública, devido ao contato da população com a água, normalmente, contaminada, bem como o aumento dos casos de dengue.

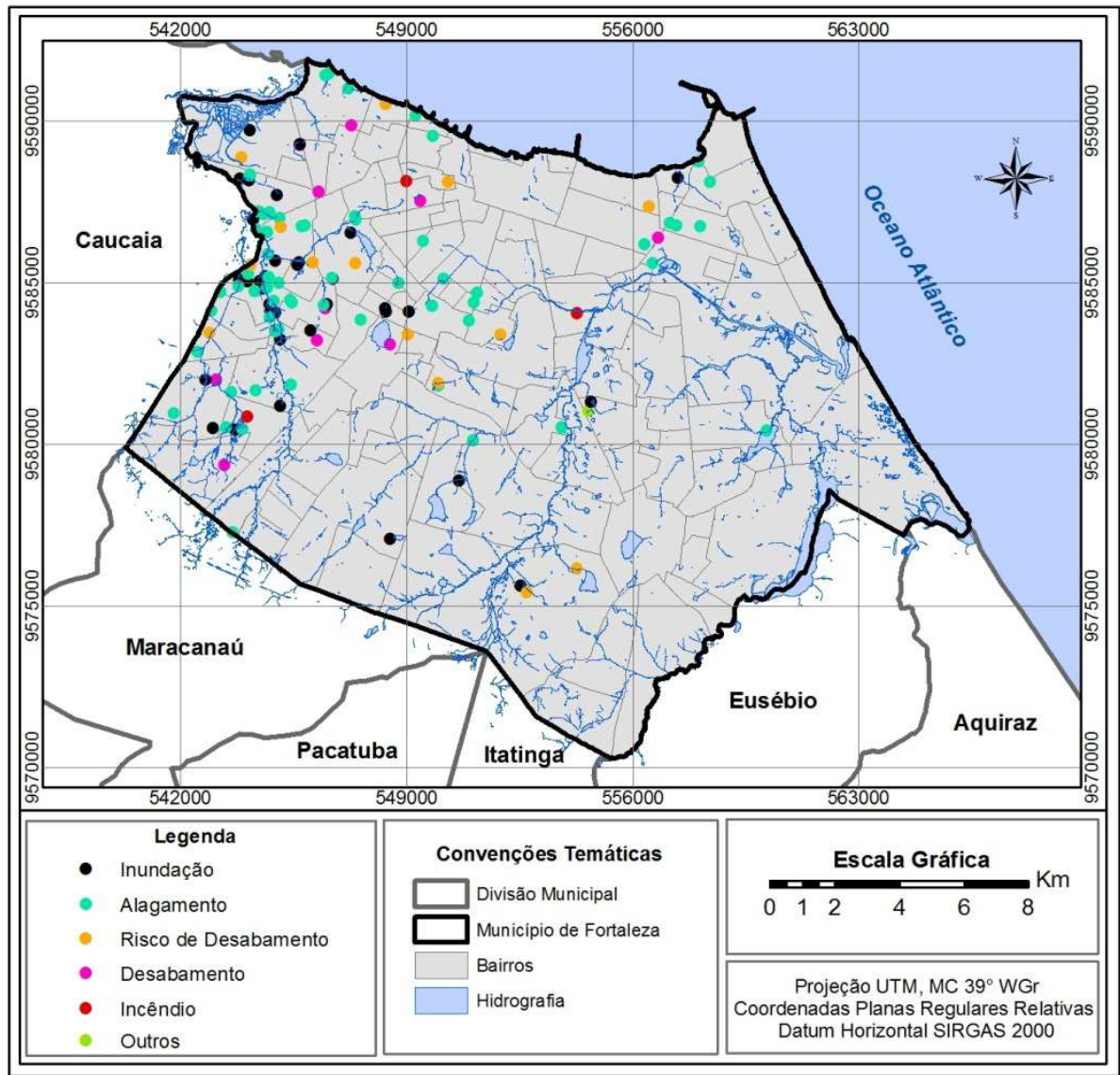

Figura 10- Mapa de localização das ocorrências de impactos hidrometeóricos para o episódio de 27.03.2012. Fonte de dados: Defesa Civil de Fortaleza.

Um dos fatores intensificadores da amplitude espacial das inundações e alagamentos resulta do acúmulo de resíduos sólidos nas galerias pluviais e nos canais das drenagens, os quais obstruem a livre circulação das águas, além de constituírem locais propícios à proliferação de vetores de doenças. 
Tabela 1 - Tipologias dos impactos hidrometeóricos e bairros mais afetados

\begin{tabular}{l||c||l}
\hline Tipologia de Ocorrência & Quantidade & \multicolumn{1}{c}{ Bairros mais impactados } \\
\hline Inundação & 50 & Quintino Cunha, Genibaú, Autran Nunes e Bom Jardim \\
\hline Alagamento & 73 & Genibaú, Quintino Cunha e Dom Lustosa, \\
\hline Incêndio & 4 & Água Fria, Bom Jardim, Monte Castelo e Dom Lustosa \\
\hline Deslizamento & 1 & Vila Velha \\
\hline Desabamento & 10 & $\begin{array}{l}\text { Pici, Parangaba, Henrique Jorge, João XXIII, Cocó, São } \\
\text { Geraldo, Siqueira, Barroso e Jardim Iracema }\end{array}$ \\
\hline Risco de Desabamento & 15 & Genibaú e Jangurussu \\
\hline Outros & 1 & Cidade dos Funcionários \\
\hline
\end{tabular}

Fonte de dados: Defesa Civil de Fortaleza.

Embora haja razoável conhecimento dos problemas decorrentes da poluição dos corpos hídricos, a população que vive em risco, por uma série de fatores, não toma iniciativa e nem recebe, de forma eficiente, as soluções das entidades públicas. Muitos fatores explicam esta situação, mas algumas tomam nuanças mais significativas. Cita-se que em alguns casos os indivíduos que vivem em risco sabem das consequências advindas das chuvas extremas, mas por estes impactos serem uma possibilidade de ocorrência a população prefere conviver com o risco, pois há a garantia da residência, mesmo que de forma ilegal. Há também uma precariedade no conhecimento da população, motivada pela falta de experiência vivida com as inundações, pelo baixo nível educacional e reduzido acesso às informações, entre outros.

Em seguida, os impactos mais registrados foram riscos de desabamento, desabamentos e incêndios, estando relacionados às ocupações próximas dos corpos hídricos, de pontos de alagamentos ou resultado da precariedade das residências, comumente construídas com materiais impróprios. Os incêndios são provocados pela associação entre os materiais de fácil combustão utilizados nas moradias, pela precariedade do sistema elétrico, por vezes ilegais, e pela situação das residências, normalmente com infiltrações, gotejamentos ou mesmo inundadas. Também foi registrada a ocorrência de deslizamento nas dunas no bairro Vila Velha.

Os bairros que mais registraram impactos foram: Genibaú, Quintino Cunha, Dom Lustosa e Autran Nunes, todos integrantes da bacia do rio Maranguapinho/Ceará e estando associado à ocupação das planícies de inundação destes cursos d'água.

Ressalta-se que a cidade passou por outros danos, embora de menor magnitude, de modo que não foram informados à Defesa Civil, como a abertura de buracos nas vias Geo UERJ - Ano 15, no. 24, v. 1, $1^{\circ}$ semestre de 2013 p. 181-206 ISSN: 1415-7543E-ISSN: 1981-9021

http://www.e-publicacoes.uerj.br/index.php/geouerj 
eacidentes de trânsito. Em alguns bairros não foi registrada nenhuma manifestação de impactos, com destaque àqueles situados nos setores sul, nordeste e sudeste da cidade, locais menos afetados pelo sistema atmosférico. Além disso, porções destes setores são habitadas por grupos mais abastadas da cidade, portanto menos vulneráveis às adversidades climáticas.

\section{Considerações finais}

Diante da problemática, das discussões e dos produtos apresentados, constatouse que o espaço urbano de Fortaleza é extremamente heterogêneo, revelando as contradições socioespaciais e socioambientais presentes neste território, produzidas pela vulnerabilidade socioambiental presente em cada parcela da cidade.

Neste sentido, as vulnerabilidades e os riscos se acentuam durante a ocorrência de episódios pluviais extremos, como o ocorrido no dia 27.03.2012. Este evento foi formado, em macro escala, pela associação da ZCIT com um VCAS, sendo que em meso escala a instabilidade produziu um $\mathrm{CCM}$, resultando em uma precipitação excepcional. A análise da distribuição geográfica das chuvas revelou que estas se concentraram, sobretudo na zona oeste de Fortaleza, região predominantemente habitada por populações mais vulneráveis, principalmente aquelas residentes nas planícies da bacia dos rios Maranguapinho e Ceará, de modo, que os principais impactos foram as inundações e os alagamentos das moradias e das vias de circulação, além de danos estruturais ao patrimônio público e privado.

Nestes termos, o estudo dos riscos e vulnerabilidades passa essencialmente por uma abordagem que busque analisar de forma integrada o complexo jogo de relações mantidas entre a sociedade, principalmente a urbana, e a natureza, visando o entendimento da problemática existente, bem como a criação de propostas aplicáveis para a solução da mesma, dentro de uma gestão integrada em todos os níveis de planejamento e de tomada de decisão.

Geo UERJ - Ano 15, no. 24, v. 1, $1^{\text {o }}$ semestre de 2013 p. 181-206 ISSN: 1415-7543E-ISSN: 1981-9021

http://www.e-publicacoes.uerj.br/index.php/geouerj 


\section{Referências}

COSTA, M. C. L. Fortaleza: expansão urbana e organização de espaço. In: SILVA, J. B; CAVALCANTE, T. C; DANTAS, E. W.C. (Org.). Ceará: um novo olhar geográfico. 2. ed. Fortaleza: Demócrito Rocha, 2007.

DEFESA CIVIL MUNICIPAL DE FORTALEZA. Relatório Interno. Fortaleza, 2012.

DESCHAMPS, M. V. Vulnerabilidade Socioambiental na Região Metropolitana de Curitiba. Curitiba: UFPR, 2004. 155p. Tese de Doutorado em Meio Ambiente e Desenvolvimento, Universidade Federal do Paraná, Curitiba, 2004.

FERREIRA, A. G.; MELLO, N. G. S. Principais sistemas atmosféricos atuantes sobre a região nordeste do Brasil e a influência dos oceanos pacífico e atlântico no clima da região. Revista Brasileira de Climatologia. Presidente Prudente, v. 1, n. 1, p. 15-28, 2005.

INTERNATIONAL STRATEGY FOR DISASTER REDUCTION - ISDR. Living with risk: a global review of disaster reduction initiatives. Geneva: UN/ISDR, 2004.

MAGALHÃES, G. B; ZANELLA, M. E. Comportamento Climático da Região Metropolitana de Fortaleza. Revista Mercator, Fortaleza, v. 10, n. 23, p. 129-145, 2011.

MARCUZZO, F. F. N; ANDRADE, J. R; MELO, D. C. R. Métodos de interpolação matemática no mapeamento das chuvas do Estado do Mato Grosso. Revista de Geografia Física, n. 4, p. 793-804, 2011.

MENDONÇA, F. Geografia socioambiental. In: MENDONÇA, F; KOZEL, S. (Org.).Elementos de epistemologia da geografia contemporânea. Curitiba: Ed. da UFPR, 2002.

Riscos, vulnerabilidade e abordagem socioambiental urbana: uma reflexão a partir da RMC e de Curitiba. Revista Desenvolvimento e Meio Ambiente, n. 10, p. 139148, 2004.

Riscos e vulnerabilidades socioambientais urbanos: a contingência climática. Revista Mercator, v. 9, n. 1, p. 153-163, 2010.

Riscos, vulnerabilidades e resiliência socioambientais urbanas: inovações da análise geográfica. Revista da ANPEGE, v.7, n. 1, p. 111-118, 2011.

MENDONÇA, F; DANNI-OLIVEIRA, I. M. Climatologia: noções básicas. São Paulo: Oficina de Textos, 2007.

Geo UERJ - Ano 15, nº 24, v. 1, $1^{\circ}$ semestre de 2013 p. 181-206

ISSN: 1415-7543E-ISSN: 1981-9021

http://www.e-publicacoes.uerj.br/index.php/geouerj 
MOLION; J. C. B; BERNARDO, S. O. Uma revisão da dinâmica das chuvas no Nordeste brasileiro. Revista Brasileira de Meteorologia, v.7, n. 1, p. 1-10, 2002.

MONTEIRO, C. A. F. Teoria e Clima Urbano: um projeto e seus caminhos. In: MONTEIRO, C. A. F; MENDONÇA, F. (Org.). Clima Urbano. São Paulo: Contexto, 2011.

Teoria e Clima Urbano. São Paulo: Universidade de São Paulo/ Instituto deGeografia, 1976.

MONTEIRO, J. B. Chover, mas chover de mansinho: desastres naturais e chuvas extremas no Estado do Ceará. Fortaleza: UECE, 2011, 198p. Dissertação de Mestrado em Geografia, Universidade Estadual do Ceará, Fortaleza, 2011.

MOURA, M. O. O clima urbano de Fortaleza sob o nível do campo térmico. UFC, 2008. 318p. Dissertação de MestradoGeografia, Universidade Federal do Ceará, 2008.

REBELO, F. Um novo olhar sobre os riscos? O exemplo das cheias rápidas (Flash Floods) em domínio mediterrâneo. Territorium, v. 15, p. 7-14, 2008.

VEYRET, Y; RICHMOND, N. M. O risco, os riscos. In: VEYTET, Y (Org.). Os riscos: o homem como agressor e vítima do meio ambiente. São Paulo: Contexto, 2007.

XAVIER, T. M. B. S. Tempo de Chuva: estudos climáticos e de previsão para o Ceará e Nordeste Setentrional. Fortaleza: ABC Editora, 2001.

Chuvas em janeiro e fevereiro 2004 no Ceará e dificuldades para previsão durante os anos neutros no Pacífico. In: Congresso Brasileiro de Meteorologia, 13., 2004. Fortaleza. Anais... Fortaleza: CBM, 2004.

ZANELLA, M. E. As características climáticas e os recursos hídricos do Ceará. In: SILVA, J. B; CAVALCANTE, T. C; DANTAS, E. W.C. (Org.). Ceará: um novo olhar geográfico. 2. ed. Fortaleza: Demócrito Rocha, 2007.

ZANELLA, M. E; MELLO, N. G. S. Eventos pluviométricos intensos em ambiente urbano: Fortaleza, episódio do dia 29/01/2004. In: SILVA, J. B; DANTAS, E. W. C; ZANELLA, M. E; MEIRELES, A. J. A. (Org.). Litoral e Sertão: natureza e sociedade no nordeste brasileiro. Fortaleza: Expressão Gráfica, 2006.

ZANELLA, M. E; SALES, M. C. L; ABREU, N. J. A. Análise das precipitações diárias intensas e impactos gerados em Fortaleza, CE. GEOUSP - Espaço e Tempo, n. 25, p. 53-68, 2009.

ZANELLA, M. E; COSTA, M. C. D; PANIZZA A. C; ROSA, M. V. Vulnerabilidade Socioambiental de Fortaleza. In: DANTAS, E. W. C; COSTA, M. C. L. (Org.).

Geo UERJ - Ano 15, no. 24, v. 1, $1^{\circ}$ semestre de 2013 p. 181-206 ISSN: 1415-7543E-ISSN: 1981-9021

http://www.e-publicacoes.uerj.br/index.php/geouerj 
DOI: $10.12957 /$ geouerj.2013.5074

Vulnerabilidade Socioambiental: na Região Metropolitana de Fortaleza. Fortaleza: edições UFC, 2009.

Artigo recebido para publicação em janeiro de 2013.

Artigo aceito para publicação em junho de 2013.

Geo UERJ - Ano $15, \mathrm{n}^{\circ} .24$, v. $1,1^{\circ}$ semestre de 2013 p. 181-206

ISSN: 1415-7543E-ISSN: 1981-9021

http://www.e-publicacoes.uerj.br/index.php/geouerj 